j.otc.2008.01.016

2. Ganly I, Patel SG, Matsuo J, et al. Analysis of postoperative complications of open partial laryngectomy. Head Neck. 2009;31(3):338-345. doi:10.1002/hed.20975

3. Tống Xuân Thắng. Các biến chứng và di chứng sau cắt một phần thanh quản trên nhẫn có tạo hình kiểu nhẫn - móng - thanh thiêtt. Tap chí Tai Mũi Họng Việt Nam. 2013;58-13:33-38.

4. Lê Minh Kỳ. Nghiên cứu ứng dung phẫu thuât cắt bán phần thanh quản Tucker trong điêu trị ung thư thanh quản. Tạp Chí Học Việt Nam. 2012;tâp 392:43-46.

5. Aghajanzadeh M, Dehnadi A, Ebrahimi $\mathbf{H}$, et al. Classification and Management of
Subcutaneous Emphysema: a 10-Year Experience. Indian J Surg. 2015;77(S2):673-677. doi:10.1007/s12262-013-0975-4

6. Gallo 0 , Locatello LG, Larotonda G, Napoleone V, Cannavicci A. Nomograms for prediction of postoperative complications in open partial laryngeal surgery: GALLO ET AL.J Surg Oncol.

2018;118(6):1050-1057. doi:10.1002/jso.25232

7. Lucioni $M$, Bertolin A, Lionello $M$, et al. Transoral laser microsurgery for managing laryngeal stenosis after reconstructive partial laryngectomies: TLM for Postoperative Laryngeal Stenosis. The Laryngoscope. 2017;127(2):359365. doi:10.1002/lary.26056

\title{
ĐÁNH GIÁ HIÊU QUẢ IN VITRO CỦA CÁC PHỐI HỢP KHÁNG SINH TRÊN PHẾ CẦU GÂY VIÊM PHỔI CộNG ĐÔNG Ở TRẺ EM
}

\author{
Nguyễn Thị Nam Phong*, Phạm Viết Tín*, \\ Võ Đình Sơn*, Trần Thị Thúy Nga*, Đỗ Thị Hồng Tươ***
}

\section{TÓM TẮT}

Đặt vấn đề: Kháng sinh và các phác đồ phối hợp là các liệu pháp chính trong điều trị viêm phổi cộng đồng (VPCĐ). Trước những thách thức gia tăng nhanh chóng các chủng vi khuẩn phế cầu (PC) đa đề kháng tại Việt Nam, cần thiết phải đánh giá lại hiêu quả của các phối hợp kháng sinh nhằm hồ trợ kiếm soát đề kháng kháng sinh và lựa chọn liệu pháp điêu trị phù hơp. Mục tiêu nghiên cứu: Khảo sát sự hiêp đồng tác dụng của một số phối hợp kháng sinh đang được sử dụng trong điêu tri VPCĐ ở trẻ em trên các chủng phế cầu đa kháng. Phương pháp nghiên cứu: Nghiên cứu thực nghiêm đánh giá hiệu quả hiêp lực tác động của một sổ cặp phối hợp kháng sinh trên phế cầu đa kháng bằng phương pháp E-Test. Kết quả: Sự hiện diện của azithromycin, gentamicin làm giảm MIC của các kháng sinh sử dung trong phối hợp với cefotaxim, ceftriaxon trên chủng PC. Các kháng sinh trong các cặp phối hợp (gentamycin + cefotaxim) và (gentamicin + ceftriaxon) làm tăng tác dụng hồ trợ lần nhau trên chủng PCa, tuy nhiên chưa có tác dụng hiệp lực rõ ràng. Các cặp phối hợp macrolid và beta-lactam chưa thể hiện được tác dụng hiệp đồng diệt khuẩn in vitro. Kết luận: Trong trường hợp VPCĐ do phế cầu đa kháng thuốc, các phối hợp giửa nhóm macrolid và beta-lactam không đem lại hiệu quả hiêp lực tác động in vitro so với kháng sinh riêng lẻ. Các bác sĩ lâm sàng có thể cân nhắc lựa chọn các cặp kháng sinh phù hợp để nâng cao hiệu quả điều trị.

Tư khóa: Phối hợp kháng sinh, in vitro, E-test, viêm phổi cộng đồng, phế cầu khuẩn

\footnotetext{
*Trường Đại học Kỹ thuâat Y-Dược Đà Nã̃ng

**Dai hoc Y Dước Thành phố Hî̀ Chí Minh

Chịu trách nhiệm chính: Đố Thị Hồng Tươi

Email: hongtuoi@ump.edu.vn

Ngày nhận bài: 22.6.2021

Ngày phản biên khoa hoc: 19.8.2021

Ngày duyệt bài: 25.8.2021
}

\section{SUMMARY}

IN-VITRO EFFICACY EVALUATION OF ANTIMICROBIAL COMBINATION ON PNEUMOCOCCAL-INFECTED- COMMUNITYACQUIRED PNEUMONIA IN CHILDREN

Introduction: Antibiotics and combination regimens are of importance in the treatment of Community-Acquired Pneumonia (CAP). In the face of the rapid emergence of multidrug-resistant pneumococcal strains, it is necessary to re-evaluate the efficacy of combination therapies to support controlling antimicrobial resistance and selecting appropriate regimens for the treatment of CAP. Objectives: To investigate the synergistic effect of some commonly used combination therapy for the treatment of CAP on multidrug-resistant pneumococcal isolates. Methods: The experimental study was conducted to evaluate the synergistic effects of several dual antimicrobial therapies on multidrugresistant pneumococcal isolates using E-test methods. Results: The presence of azithromycin, gentamicin reduced the MIC of antibiotics used in combination with cefotaxime, ceftriaxone on the pneumococcal strains. Gentamicin-plus-cefotaxime and gentamicinplus-ceftriaxone combinations showed the additive antimicrobial effects on the pneumococcal strain Pca; however, there were no clear synergistic activities. Macrolide and beta-lactam combinations have not shown in vitro synergistic bactericidal effects. Conclusions: In the case of CAP induced by multidrug-resistant Streptococcus pneumoniae, combining macrolides and $\beta$-lactams does not produce in vitro synergistic effects. The clinicians should carefully consider the selection of appropriate antibiotic combinations to enhance the treatment efficacy.

Keywords: Combination therapy, in vitro, E-test, Community-Acquired Pneumonia, Streptococcus pneumoniae 


\section{I. ĐĂT VẤN ĐỀ}

Viêm phổi mắc phải ở công đồng (VPCĐ) là một trong những nhiễm khuẩn nghiêm trọng, gây ra hàng triệu cái chết ở trẻ em trên thế giới mối năm. Tại Việt Nam, Bộ Y tế ước tính hằng năm nhiễm khuấn này nguyên nhân của khoảng 4000 trường hợp tử vong ở trẻ em dưới 5 tuổi [1]. Tác nhân vi khuẩn phổ biến nhất gây VPCĐ là Streptococcus pneumoniae (Phế cầu). Theo hướng dẫn điều trị của Bộ Y tế Việt Nam, amoxicilin đơn trị là lựa chọn ưu tiên hàng đâu để điều trị các trường hợp VPCĐ ở trẻ em [1]. Tuy nhiên, môt số trường hợp VPCĐ được khuyến cáo sử dung các phối hợp kháng sinh. Hiệu quả của việc sử dung liệu pháp phối hợp kháng sinh là một vấn đề cần được thảo luận và nghiên cứu để có thể kết luận chính xác mặc dù một số báo cáo cho thấy lợi ích của việc phối hợp kháng sinh trong điều trị VPCĐ trên lâm sàng [2]. Tuy nhiên, hiện nay, các chủng phế cầu đề kháng với các kháng sinh $\beta$-lactam và đa đề kháng đang gia tăng nhanh chóng tại Việt Nam [3]. Điều này có thể dẫn đến nhiều hớn những thất bại lâm sàng và đặt ra những thách thức trong viểc lựa chọn kháng sinh điêu trị. Vì vây, đề tài này được thực hiện nhằm khảo sát hiệu quả hiệp đồng của một số cặp phối hợp kháng sinh đang được sử dụng trên lâm sàng, từ đó cung cấp những dữ liệu cân thiết làm cơ sở cho viêc lựa chon liệu pháp kháng sinh hợp lý trong điều trị VPCĐ.

\section{II. ĐỐI TƯỢNG VÀ PHƯƠNG PHÁP NGHIÊN CỨU}

Nghiên cứu thực nghiệm xác định sự hiệp lực tác động (theo phương pháp E-test) của các phối hợp kháng sinh được sử dụng trong lâm sàng trên 2 chủng phế cầu khuẩn đa kháng thuốc (PCa và $\mathrm{PCb}$ ) được phân lập từ mẫu bệnh nhân trên bệnh nhân nhi được chẩn đoán viêm phổi công đồng tại Bênh viển Nhi tỉnh Quảng Nam năm 2018 (phể duyệt tại Quyết định số 2078/QĐ-UBND ngày 06/07/2018). Các cặp phối hợp kháng sinh được nghiên cứu gồm: azithromycin + ceftriazon, azithromycin + cefotaxim, erythromycin + cefotaxim, gentamicin + ceftriaxon, gentamicin + cefotaxim, vancomycin + ceftriaxon. Các thanh E-Test (BioMérieux, Hoa Kỳ) chứa các kháng sinh trên; môi trường Blood Agar, Mueller-Hinton Agar (MHA) với $5 \%$ máu cừu, chủng kiểm soát $S$. pneumoniae ATCC 49619 và các trang thiết bi nuôi cấy vi khuẩn được chuẩn bi. Quy trình thực hiện theo hướng dẫn CLSI M07-A9 (Clinical and Laboratory Standards Institute) [4] và của nhà sản xuất [5]. Pha huyền dịch vi khuẩn đat độ đục chuẩn 0,5 McFarland và trải đều lên mắt đĩa thạch máu cừu MHA, sau đó các thanh E-test chứa 2 kháng sinh khác nhau của cặp phối hợp sẽ được đặt vuông góc với nhau lên bề măt thach. Điểm cắt chính là giá tri MIC của mỗi kháng sinh trong thử nghiệm đơn trị. Sau khi ủ $16-24$ giờ trong điều kiện nhiệt độ $35^{\circ} \mathrm{C}$ và môi trường $5 \% \mathrm{CO}_{2}$, các đĩa thach đước lấy ra và quan sát kết quả. Nồng độ ức chể riêng phần ( $\Sigma$ FIC) sẽ được tính dựa trên công thức:

$\Sigma \mathrm{FIC}=\mathrm{FIC}_{\mathrm{A}}+\mathrm{FIC}_{\mathrm{B}}$

Trong đó:

MIC của kháng sinh $\mathrm{A}$ (hoặc B) trong thử nghiệm phới hợp

$\mathrm{FIC}_{\mathrm{A}}$ (hoăc $\left.\mathrm{B}\right)=$ MIC wủa khẩng sinh $A$ (hoọ̆c $B$ ) trong thử nghiệm đon lê

Biện giải kết quả: Nếu FIC $\leq 0,5: 2$ kháng sinh có tác dụng hiệp lực; $0,5<$ FIC $\leq 1$ : 2 kháng sinh có tác dụng bổ trợ; $1<$ FIC $\leq 4$ : 2 kháng sinh khi phối hợp không tạo ra được sự khác biệt trên in vitro; FIC > 4: 2 kháng sinh có tác dụng đối kháng

\section{KẾT QUẢ NGHIÊN CỨU}

Kết quả bảng 1 cho thây 2 chủng $\mathrm{PCa}$ và $\mathrm{PCb}$ đã đề kháng với các kháng sinh macrolid với trị số MIC cao $(256 \mu \mathrm{g} / \mathrm{mL})$. Đối với các kháng sinh nhóm $\beta$-lactam, phế cầu $\mathrm{PCa}$ và $\mathrm{PCb}$ đã không nhạy cảm với penicillin $G$ và ceftriaxon. Mặc dù 2 chủng này vẫn còn nhay cảm với cefotaxim, tuy nhiên, giá trị MIC cao hơn đáng kể so với chủng kiểm soát $(1 \mu \mathrm{g} / \mathrm{mL}$ vs $0,064 \mu \mathrm{g} / \mathrm{mL})$.

Bảng 1: Giá trị MIC của một số kháng sinh đơn sử dụng trong thử nghiệm đánh giá hiệp lực

\begin{tabular}{|c|c|c|c|c|c|c|c|}
\hline \multicolumn{8}{|c|}{ MIC của các KS đơn trị $(\mu \mathrm{g} / \mathrm{mL})$} \\
\hline Kháng sinh & $\begin{array}{l}\text { Penic- } \\
\text { illin }\end{array}$ & $\begin{array}{l}\text { Erythro- } \\
\text { mycin }\end{array}$ & $\begin{array}{l}\text { Azithro- } \\
\text { mycin }\end{array}$ & $\begin{array}{l}\text { Vanco- } \\
\text { mycin }\end{array}$ & $\begin{array}{l}\text { Genta- } \\
\text { micin }\end{array}$ & $\begin{array}{c}\text { Cefotax- } \\
\text { im }\end{array}$ & $\begin{array}{l}\text { Ceftri- } \\
\text { axon }\end{array}$ \\
\hline Chủng PCa & 3 & 256 & 256 & 0.19 & 16 & 1 & 1.5 \\
\hline Chủng PCb & 3 & 256 & 256 & 0.25 & 8 & 1 & 1.5 \\
\hline $\begin{array}{l}\text { Chủng S. pneumoniae } \\
\text { ATCC } 49619\end{array}$ & 0,38 & 0,125 & 1,5 & 0,19 & 12 & 0,064 & 0,25 \\
\hline
\end{tabular}


Thử nghiệm đánh giá tác dụng hiệp lực của một số cặp kháng sinh được sử dụng phổ biến trên lâm sàng

Các giá trị FIC của các kháng sinh đơn và giá trị $\Sigma$ FIC của từng phối hợp trên các chủng $\mathrm{PCa}$ và $\mathrm{PCb}$ được tính toán và tổng hợp tại bảng 2 .

Bảng 2. Giá trị FIC của mối kháng sinh trong phôi hợp và trị số IFIC

\begin{tabular}{|c|c|c|c|c|}
\hline Chủng phế câu & FIC A & FIC B & EFIC & Biện giải \\
\hline \multicolumn{5}{|c|}{ Azithromycin (A) + Ceftriaxone (B) } \\
\hline PCa & 1,00 & 1,00 & 2,00 & Không khác biêtt \\
\hline $\mathrm{PCb}$ & 1,00 & 1,00 & 2,00 & Không khác biệt \\
\hline \multicolumn{5}{|c|}{ Azithromycin (A) + Cefotaxime (B) } \\
\hline $\mathrm{PCa}$ & 1,00 & 0,75 & 1,75 & Không khác biêt \\
\hline $\mathrm{PCb}$ & 1,00 & 1,00 & 2,00 & Không khác biềt \\
\hline \multicolumn{5}{|c|}{ Erythromycin (A) + Cefotaxime (B) } \\
\hline PCa & 1,00 & 1,00 & 2,00 & Không khác biệt \\
\hline $\mathrm{PCb}$ & 1,00 & 1,00 & 2,00 & Không khác biệt \\
\hline \multicolumn{5}{|c|}{ Gentamicin (A) + Ceftriaxone (B) } \\
\hline PCa & 0,50 & 0,50 & 1,00 & Tác dụng hô trợ \\
\hline $\mathrm{PCb}$ & 1,00 & 0,50 & 1,50 & Không khác biệt \\
\hline \multicolumn{5}{|c|}{ Gentamicin (A) + Cefotaxime (B) } \\
\hline PCa & 0,25 & 0,38 & 0,63 & Tác dụng hô trợ \\
\hline $\mathrm{PCb}$ & 1,00 & 0,50 & 1,50 & Không khác biệt \\
\hline \multicolumn{5}{|c|}{ Vancomycin (A) + Ceftriaxone (B) } \\
\hline PCa & 0,66 & 1,00 & 1,66 & Không khác biêtt \\
\hline $\mathrm{PCb}$ & 0,76 & 0,67 & 1,43 & Không khác biệt \\
\hline
\end{tabular}

Kết quả bảng 2 cho thây việc kết hợp thêm azithromycin làm giảm nhẹ giá trị MIC của cefotaxim trong thử nghiệm trên chủng $\mathrm{PCa}$. Tuy nhiên, giá trị $\Sigma F I C$ lớn hơn 0,5 (không có sự tương tác giữa hai kháng sinh). Nhìn chung, các cặp phối hợp của các kháng sinh macrolid và $\beta$ lactam chưa thể hiện hiệp đồng tác dụng trên các chủng phế cầu thử nghiệm. Đối với sự phối hợp của gentamicin và các cephalosporin thế hệ III, kết quả nghiên cứu cho thấy các phối hợp này đã làm giảm trị số MIC của các kháng sinh riêng lẻ. Trên chủng $\mathrm{PCa}$, thử nghiệm cho thấy có tác dụng hỗ trợ lẫn nhau giữa các cặp phối hợp gentamicin + ceftotaxim và gentamicin + ceftriaxon. Nghiên cứu cho thấy sự phối hợp của vancomyin và ceftriaxon đã làm giảm giá trị MIC của các kháng sinh riêng lẻ, tuy nhiên phối hợp này chưa thể hiện rõ tác động hiệp lực.
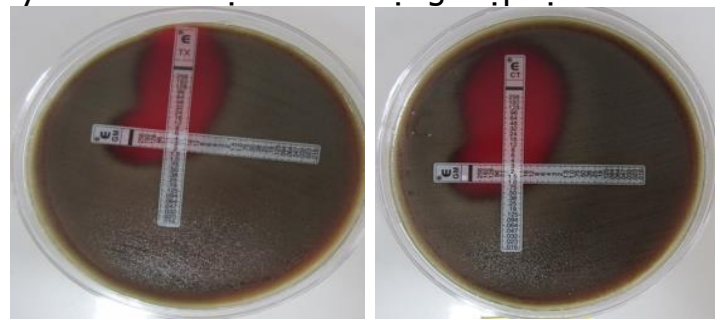

Hình 1: Thử tác dụng hiệp lực in-vitro của các phối hợp kháng sinh (trên chủng PCa các phối hợp trên cho thấy có sự bổ trợ tác dụng) (GM: Gentamicin; TX: Ceftriaxone; CT: Cefotaxime)

\section{BÀN LUẬN}

Sự phối hợp của các kháng sinh nhóm macrolid và $\boldsymbol{\beta}$-lactam: Sự có mặt của azithromycin đã làm giảm giá trị MIC của cefotaxim trên chủng $\mathrm{PCa}$. Tuy nhiên, nhìn chung việc phối hợp azithromycin hay erythromycin với các kháng sinh $\beta$-lactam không tạo ra được tác dụng hiệp đồng diệt khuẩn. Nghiên cứu in vitro của Lin và cộng sự (2003) sử dụng 2 phương pháp checkerboard và time-kill trên 11 chủng phế cầu cho thây những dữ liệu tương tự [7]. Kết quả cho thấy các kháng sinh macrolid và beta-lactam thể hiện hoạt động ức chế vi khuẩn một cách riêng lẻ và không thể hiện sự hiệp đồng tác dụng giữa chúng.

Mặc dù sự hiệp đồng tác dụng không được thấy trên in vitro, một số nghiên cứu hồi cứu cho thây lợi ích lâm sàng khi sử dụng phối hợp kháng sinh này so với liệu pháp đơn trị [2]. Sự khác biệt giữa kết quả quan sát được trên in vitro và in vivo có thể do một số yếu tố như tính toàn vẹn của tế bào vật chủ và đáp ứng miễn dịch, vị trí và độ nặng của nhiễm trùng, độc lực và số lượng của vi khuẩn hiện diện, loại và liều lượng kháng sinh được sử dụng [8]. Ngoài ra, lợi ích lâm sàng của phối hợp này có thể không đến từ sự hiệp đồng diệt khuẩn, mà là nhờ vào đặc tính kháng viêm của các macrolid thông qua việc điều chỉnh hoạt động giải phóng interleukin-8 ở các tế 
bào biểu mô đường hô hấp. Ngoài ra, các macrolid cũng có khả năng ức chế các nội độc tố được sản sinh trong quá trình phế cầu bị phân hủy do tác dụng diệt khuẩn của kháng sinh $\beta$ lactam hoăc vancomycin [2]. Các phối hợp này có thể có lợi trên các chủng không điển hình tại vị trí nhiễm trùng nhằm cung cấp một phổ kháng khuẩn tốt hơn so với việc chỉ sử dụng kháng sinh $\beta$-lactam trong liệu pháp đơn trị [2]. Do đó, các nhà điều trị có thể xem xét việc sử dụng liệu pháp phối hợp trong các trường hợp viêm phổi nặng, viêm phổi có biến chứng, hoặc không đáp ứng với liệu pháp ban đầu. Việc xây dựng các mô hình phù hợp để chứng minh lợi ích tiềm năng của cặp phối hợp này trên in vivo là điều cần thiết.

Sự phối hợp của gentamicin và một số cephalosporin thế hệ III. Gentamicin và các ß-lactam là cặp phối hợp kháng sinh điển hình được sử dụng phổ biển trên lâm sàng. Tuy nhiên, hiệu quả lâm sàng của phối hợp này đến nay là một vấn đề cần thảo luận, nghiên cứu thêm. Kết quả nghiên cứu in vitro trong đề tài này cho thấy việc phối hợp gentamicin cùng ceftriaxon hoặc cefotaxim đã làm giảm giá trị MIC của các kháng sinh trong phối hợp. Tuy nhiên, các giá trị $\Sigma$ FIC đều lớn hơn 0,5. Do đó, phối hợp này không thể hiện được tác dụng hiệp đồng diệt khuẩn trên các chủng phế câu thử nghiệm. Nghiên cứu được thực hiện gần đây bởi Ruppen và cộng sự (2017) cho thấy một kết quả tương tự trên in vitro [9]. Ngoài ra, nghiên cứu tổng quan có hệ thống của Paul và công sự (2014) thống kê 69 thử nghiệm lâm sàng trên 7863 bệnh nhân cũng đã cho thấy rằng việc kết hợp 1 kháng sinh aminoglycosid như gentamicin với kháng sinh $\beta$-lactam không thể hiện sự khác biệt trong điều trị so với liệu pháp đơn trị betalactam. Sự có mặt của aminoglycosid có thể làm tăng thêm những tác dụng phụ không mong muốn trên tai và thâan [10].

Vì vậy, trong trường hợp VPCĐ mà nguyên nhân gâyy bệnh đã được xác định là phế cầu khuẩn, đề tài không khuyến cáo sử dụng phối hợp này để điêuu trị vì không thể hiện được hiệp đồng tác dụng và lợi ích lâm sàng rõ rệt trong khi có nguy cơ làm tăng tác dụng phụ. Tuy nhiên, trong một số trường hợp, cụ thể như viêm phổi nặng, có biến chứng, hoặc không đáp ứng với liệu pháp điều trị ban đầu, hoặc chưa xác định được nguyên nhẩn gây bệnh và nghi ngờ có sự tham gia của vi khuẩn gram âm, phối hợp này có thể được các nhà lâm sàng cân nhắc sử dụng.

Sự phối hợp của vancomycin và ceftriaxone. Thử nghiệm in vitro trong nghiên cứu này cho thấy mặc dù sự kết hợp vancomycin và ceftriaxone đã làm giảm MIC các kháng sinh thành phần, tuy nhiên, không có hiệp đồng tác dụng giữa hai kháng sinh này (các trị số $\Sigma F I C$ đều lớn hơn 0,5 ). Nghiên cứu của Ribes và cộng sự (2005) trên các chủng phế cầu đa đề kháng báo cáo sự phối hợp của vancomycin và ceftriaxon không tạo ra được hiệp đồng tác dụng.

Hiện nay, trên thế giới chưa xuất hiện các chủng phế cầu đề kháng với vancomycin. Do đó, việc sử dụng phối hợp vancomycin với các cephalosporin phổ rộng để điều trị VPCĐ gây nên bởi các chủng $S$. pneumoniae đa đề kháng là không cần thiết. Tuy nhiên, trong những nhiễm khuẩn nghiêm trọng do phế cầu tại vị trí mà vancomycin khó tiếp cận như viêm não gây ra bởi các chủng phế cầu đa đề kháng hoặc đề kháng cao với $\beta$-lactam, việc phối hợp vancomycin và ceftriaxon có thể cho phép các bác sĩ giảm liều của các kháng sinh thành phần và có được hiệu quả điều trị tốt hơn.

\section{KẾT LUẬN}

Thử nghiệm cho thấy một số phối hợp kháng sinh có thể làm giảm giá trị MIC của từng kháng sinh riêng lẻ trên các chủng $S$. pneumoniae đa đề kháng. Tuy nhiên, các phối hợp kháng sinh trong nghiên cứu chưa thể hiện tác dụng hiệp đồng diệt khuẩn in vitro. Do đó, bác sĩ lâm sàng có thể cân nhắc giữa hiệu quả lâm sàng và tác dụng không mong muốn của các kháng sinh để lựa chọn phối hợp kháng sinh phù hợp, nâng cao hiệu quả điều trị VPCĐ cho trẻ em.

\section{TÀI LIÊU THAM KHẢO}

1. Ngưyễn TX, Lương $N K$, Trân $Q$, Hoàng TKH. Hướng dẫn sữ dụng kháng sinh. Hầ Nội: Nhà xuất bản Y hoc; 2015.

2. Caballero J, Rello J. Combination antibiotic therapy for community-acquired pneumonia. Annals of intensive care. 2011;1:48.

3. Larsson M, Nguyen $H Q$, Olson L, Tran TK, Nguyen TV, Nguyen CTK. Multi-drug resistance in Streptococcus pneumoniae among children in rural Vietnam more than doubled from 1999 to 2014. Acta Paediatrica. 2021;110(6):1916-23.

4. M07-A9 C. Methods for Dilution Antimicrobial Susceptibility Tests for Bacteria That Grow Aerobically. Edition N, editor: Wayne, PA: Clinical and Laboratory Standards Institute; 2012.

5. Liofilchem. MIC Test Strip Technical Sheet Synergy Testing 2016. Available from: http://www.liofilchem.net/login.area.mic/technical sheets/MTS31.pdf.

6. M100-S21 C. Performance Standards for Antimicrobial Susceptibility Testing. Edition AS-S, editor. Wayne: Clinical and Laboratory Standards Institude; 2011. 
7. Lin E, Stanek RJ, Mufson MA. Lack of synergy of erythromycin combined with penicillin or cefotaxime against Streptococcus pneumoniae in vitro. Antimicrobial agents and chemotherapy. 2003;47(3):1151-3.

8. Washington JA, 2nd. Discrepancies between in vitro activity of and in vivo response to antimicrobial agents. Diagnostic microbiology and infectious disease. 1983;1(1):25-31.
9. Ruppen $\mathbf{C}$, Decosterd $\mathbf{L}$, Sendi $\mathbf{P}$. Is gentamicin necessary in the antimicrobial treatment for group B streptococcal infections in the elderly? An in vitro study with human blood products. Infectious diseases (London, England). 2017;49(3):185-92.

10. Paul M, Lador A, Grozinsky-Glasberg S Leibovici L. Beta lactam antibiotic monotherapy versus beta lactam-aminoglycoside antibiotic combination therapy for sepsis. Cochrane Database of Systematic Reviews. 2014(1).

\title{
HIỆU QUẢ VÀ Độ AN TOÀN CỦA XA TRI LÂ̂P THỂ ĐİNH VỊ THÂN TRONG ĐIỀU TRI UNG THƯ BIỂU MÔ TẾ BÀO GAN CÓ HUYỂT KHỐI TĨNH MACH CỬA
}

\author{
Đinh Thị Ngà, Thái Doãn Kỳ, Nguyễn Anh Tuấn, \\ Nguyễn Đình Châu, Bùi Quang Biểu, Mai Thanh Bình, \\ Đinh Trường Giang, Nguyễn Văn Thái, Nguyễn Tiến Thịnh(*)
}

\section{TÓM TẮT}

Mục tiêu: Đánh giá kết quả bước đâu và độc tính của kỹ̃ thuật xạ trị lập thể định vị thân trong điều trị ung thư biểu mô tế bào gan giai đoạn tiến triển có huyết khối tĩnh mạch cửa (HKTMC). Đối tượng và phương pháp nghiên cứu: Nghiên cứu tiển cứu, theo dõi doc trên 31 bênh nhân ung thư biểu mô tế bào gan có huyết khối thân hoăc nhánh chính tĩnh mach cửa, được điều trị bằng kỹ thuật xạ trị lập thể định vị thân, theo dõi từ 07/2018 đến 06/2021 tại Bênh viện Trung Ương Quân đội 108. Đánh giá tỷ lệ đáp ứng huyết khối, thời gian sống thêm toàn bộvà̀ các tác dụng phụ. Kết quả: Tỷ lệ đáp ứng huyết khối sau 3 tháng, 6 tháng lân lượt là $67,7 \% ; 37,9 \%$. Trung vị thời gian sống thểm toàn bộ là 13 tháng. Tỷ lệ sống thêm toàn bộ sau 6 tháng, 1 năm lần lượt là 93,5\%; $54,8 \%$. Các độc tính chủ yếu độ 1-2 bao gồm giảm tiểu câu, tăng enzyme gan, đau hạ sườn phải.Không có tử vong liên quan đến điêu trị. Kết luận: Xạ trị lập thể định vị thân là phương pháp an toàn và có hiệu quả trong điều trị ung thư biểu mô tế bào gan có HKTMC.

Tứ khoá: Xa trị lập thể định vị thân, ung thư biểu mô tế bào gan, huyết khối tînh mạch cửa

\section{SUMMARY}

EFFICACY AND SAFETY OF STEREOTACTIC BODY RADIOTHERAPYFOR TREATMENT OF ADVANCED HEPATOCELLULAR CARCINOMA

WITH PORTAL VEIN THROMBOSIS

Objective: To evaluate the initial results and toxicity of stereotactic body radiotherapy (SBRT)for

(*)Bệnh viện Trung ương Quân đội 108

Chịu trách nhiệm chính: Thái Doãn Kỳ

Email: kythaitrung@gmail.com

Ngày nhận bài: 24.6.2021

Ngày phản biên khoa học: 20.8.2021

Ngày duyệt bải: 27.8 .2021 treatment ofHepatocellular Carcinoma (HCC) with Portal Vein Thrombosis (PVT). Methods: A prospective study on $31 \mathrm{HCC}$ patients with main branch or trunk portal vein thrombosis were treated by SBRT; follow-up between July, 2018 to June, 2021at Military Central Hospital 108. Ojective Response Rate (ORR), Overall Survival (OS) andtoxicitywere evaluated andanalyzed. Results: The objective response rate after 3 months and 6 months were $67.7 \%$ and $37.9 \%$, respectively. The median Overall Survival was 13 months. The overall survival rate after 6 months, 1 - year was $93.5 \%$ and $54.8 \%$. Most of toxicities were grade 1or2 including thrombocytopenia, liver enzyme elevation, abdominal pain. There was no case of treatment-related death Conclusion: SBRT is a safe and effective treatment option for advancedHCC with PVT

Keywords: Stereotactic body radiotherapy, Hepatocellular Carcinoma, Portal vein thrombosis.

\section{I. ĐĂT VẤN ĐỀ}

Ung thư biểu mô tế bào gan (UTBMTBG) là một trong những loại ung thư phổ biến nhất ở Việt Nam cũng như nhiều nước khác trên thế giới[1]. Đây là loai ung thư có tiên lượng xấu, đặc biệt ở các trường hợp ở giai đoạn tiến triển có huyết khối tĩnh mạch cửa (HKTMC). Các phương pháp điều trị truyền thống và thuốc nhắm trúng đích được coi là điều trị chuẩn cho giai đoạn này cho hiệu quả sống còn rất hạn chế. Xạ trị lập thể định vị thân (Stereotatic Body Radiation Theraphy - SBRT) là một phương phápđiều trị có nhiều ưu điểm như độ chính xác cao, cho phép tập trung liêu điều trị tại $u$, giảm tác dụng phụ trền cơ quan lành, gânđầy đãđược áp dụng tại nhiều nước trong điều trị ung thư biểu mô tế bào gan[2]. Tai Việt Nam, phương pháp này còn khá mới mẻ và mới chỉđuợc áp 